\title{
Central sleep apnoea, pathogenesis and treatment: an overview
} and perspective

\author{
W.A. De Backer
}

Central sleep apnoea, pathogenesis and treatment: an overview and perspective. W.A. De Backer. (CERS Journals Ltd 1995.

ABSTRACT: The prevalence of reported sleep disturbances in a general population is high. Many of the complaints are the result of sleep-related breathing disorders, due mainly to the occurrence of obstructive and central apnoeas. Obstructive sleep apnoea is a fully described and well-recognized entity. Central sleep apnoea (CSA) however, has been poorly studied.

There is accumulating evidence that central sleep apnoea should be considered as the end of a spectrum. Instability in the breathing pattern is the main underlying mechanism and is due to the interaction of many factors. Breathing during sleep is dependent on metabolic control and the activity of the respiratory muscles. Decreased chemical drive and/or failing respiratory muscle function are associated with CSA and usually also with ongoing hypoventilation during wakefulness, characterized by chronic daytime hypercapnia. Central respiratory drive can also be inhibited by upper airway reflexes. Mostly, however, CSA occurs as the hallmark of unstable breathing during sleep brought about by an overall increase in loop gain (especially in light sleep stages) and the unmasking of a $\mathrm{CO}_{2}$ threshold.

Arousal following central apnoeas acts as an amplification of the instability. Micro electroencephographic (EEG) arousals are often observed as a consequence of CSA. They are responsible for sleep fragmentation and hypersomnolence during the day. The daytime hypersomnolence and complaints of awakenings during sleep in patients with CSA can be striking. CSA can occur in specific pathologies, such as chronic heart failure and (post-traumatic) brain lesions, that are associated with irregular breathing.

Treatment strategies are remarkably few in number. Use of nasal ventilation and the inhalation of $\mathrm{CO}_{2}$ are mainly of theoretical interest, since patients do not often tolerate these more invasive therapies. Drug treatment, especially with acetazolamide, is easier to perform. Stimulation of upper airway reflexes, by less invasive methods, seems to be promising for the near future.

Eur Respir J., 1995, 8, 1372-1383.
Dept of Pulmonary Medicine, University of Antwerp, Belgium.

Correspondence: W. De Backer Dept of Pulmonary Medicine University of Antwerp (UIA) Universiteitsplein 1

2610 Wilrijk-Antwerpen

Keywords: Central sleep apnoea chemical drive

control of breathing

Received: February 101995

Accepted for publication March 201995
The prevalence of sleep disturbances can be studied by surveys of the general population or by objective proof with full night polysomnography, using different numbers of respiratory and sleep variables. The reported sleep disturbances in a general population are high. At least one symptom of disturbed sleep was present in $41 \%$ of all subjects in a recent survey in Tucson [1]. We recently looked at the prevalence of reported daytime sleepiness, snoring and disrupted breathing during sleep in four European cities (Reykjavik, Uppsala, Gothenburg and Antwerp), also comparing geographical variation within Europe. At all centres, 5\% of males and 2-3\% of females reported snoring every night. Daytime sleepiness was more often reported in Uppsala (odds ratio (OR) $1.6(1.2-2.1)$ than in the other centres, while daytime tiredness was most common in Reykjavik (OR 1.8 (1.42.1)). Snoring was positively correlated with age, male gender and body mass index in all areas. Remarkable associations were also found between symptoms of gastrooesophageal reflux and daytime sleepiness (OR 2.6 (1.5-4.4)), daytime tiredness (OR 4.5 (2.7-7.6)) and disrupted breathing (OR 3.8 (1.4-10)) [2]. Habitual (>3 episodes $\cdot$ week $\left.^{-1}\right)$ difficulties inducing sleep were reported by $6-9 \%$, and early morning awakenings by $5-6 \%$ of the subjects in all centres [3]. When looking at data arising from population surveys, one also has to take into account under-reporting of symptoms of disturbed breathing during sleep in females [4].

Many of the reported sleep disturbances are due to obstructive sleep apnoea (OSA). In cross-sectional studies, the minimum prevalence of OSA among men is about $1 \%$. The prevalence is highest among men aged 40-65 yrs. The highest figure reported for this age group is $9 \%$ [5]. Studies based on all night oximetry and subsequent polysomnography indicated that $5 \%$ of a general population had arterial oxygen saturation $\left(\mathrm{Sa}_{\mathrm{a}} \mathrm{O}_{2}\right)$ dip rates 
(oxygen desaturation index $(\mathrm{ODI})>4 \%$ ) of more than five per hour. Most of them had OSA, but in 10 out of 31 the cause of the $\mathrm{Sa}_{\mathrm{a}} \mathrm{O}_{2}$ dipping on the original home tracing was not elucidated [6].

Measurements using MESAM 4 (monitoring $\mathrm{Sa}_{\mathrm{a}, \mathrm{O}_{2}}$, heart rate, snoring and body position) in 349 subjects indicated that $17 \%$ of subjects were every-night snorers. In $14 \%$ more than 10 oxygen desaturations occurred per hour, and in 5\% ODI was $>20$ [7]. Recently, a random sample of 602 employed males and females, 30-60 yrs of age, were studied with full overnight polysomnography. An apnoea-hypopnoea score of $\geq 5$ was found in $9 \%$ of the females, and $24 \%$ of males. Two percent of females and $4 \%$ of males in the middle-aged group meet the minimal criteria for the sleep apnoea syndrome (apnoea/hypopnoea index (AHI) $>5$ and daytime hypersomnolence). In this study, apnoea was defined as complete cessation of airflow lasting $10 \mathrm{~s}$ or more. Hypopnoea was defined as a reduction in respiratory airflow, accompanied by a decrease of $\geq 4 \%$ in $\mathrm{Sa}_{\mathrm{a}} \mathrm{O}_{2}$ [8]. Therefore, it is not clear what the proportions of central and obstructive apnoea are. Full polysomnography in 327 patients, referred with suspicion of sleep-related breathing disorders because of snoring or daytime sleepiness, revealed an incidence of central sleep apnoea (central apnoea index (CAI) $>5$ or AHI $>10$ and obstructive apnoea index (OAI) $<5)$ of $4 \%$ [9]. It is also striking to see that in a study of 50 "normal" children and adolescents (mean age 10 yrs, range 1-17 yrs), $30 \%$ of the subjects had central apnoeas $>10 \mathrm{~s}$ in duration [10].

It is, therefore, likely that irregular breathing and central apnoeas can account for sleep disturbances among the general population, including children and young adults. We will discuss the pathogenesis and possible treatment modalities for this disease.

\section{Pathogenesis}

\section{Depressed central drive}

Rhythmic respiratory neurones in the medulla are located in a dorsal group (nucleus tractus solitarius) and a ventrolateral group (nucleus ambiguus and retroambiguus). Bilateral damage to the respiratory neurones in the medulla results in failure of automatic respiration. This was termed "Ondine's curse" [11]. Failure of automatic respiration in humans can be associated with damage to the brainstem. This was described with encephalitis, cervical cordotomy, bulbar poliomyelitis, Shy-Drager syndrome, Leigh's disease, brainstem infarction, multiple sclerosis, near-drowning and, more recently, after radiation necrosis [12].

Many mediators can have an influence on generation of central rhythm. Recently, in an animal model, endogenous "digitalis-like" factors were shown to be involved in the genesis of rapid eye movement (REM) related central apnoeas [13].

Afferent inputs from chemoreceptors and mechanoreceptors modulates the intrinsic central oscillator, to produce a respiratory pattern. Also, behavioural state (emotive, cognitive, movements, phonation) influences the central oscillator. During sleep, only chemical drive and afferents from mechanoreceptors still influence the respiratory motor out-put, directed to the pump muscles (diaphragm, intercostal, abdominal) and upper airway muscles (laryngeal, pharyngeal, hypoglossal) [14]. Many (clinical) studies indicate a crucial role for chemical afferents in the regulation of breathing during sleep.

\section{Chemical drive}

Central and peripheral chemoreceptors influence motoneuron output differently after integration at the central rhythm generator. In cats, phrenic nerve response is more dependent on central chemoreceptor input, whereas hypoglossal response is more dependent on carotid sinus chemoreceptor input [15].

Also, developmental patterns should be taken into account. Rebreathing hypercapnic and hypoxic ventilatory responses are higher during childhood than during adulthood [16]. However, in a study of 17 healthy elderly subjects and 17 younger controls, changes in $\mathrm{CO}_{2}$ drive from wakefulness to REM sleep were not significantly different between groups. The study concluded that increased incidence of respiratory disturbances during sleep in older subjects cannot be attributed to sleepinduced reduction of $\mathrm{CO}_{2}$ sensitivity [17].

The effect of the sleep stages on the magnitude of chemical drive has been studied extensively. It was recognized that sleep and hypoxia act independently, rather than interacting, in their effect on the respiratory response to $\mathrm{CO}_{2}[18,19]$. Hypercapnic ventilatory response (HCVR) was shown to be reduced in all sleep stages in 12 sleeping adults. The decrease was most pronounced during REM sleep [20]. The same authors also demonstrated that the hypoxic ventilatory response (HVR) decreased to two thirds of the wakening value in non-REM (NREM) sleep, with a further significant decrease in REM sleep [21]. The decrease in the response to hypoxia occurs only in eucapnic conditions, but is absent when hypocapnia is allowed to occur [22].

It can be questioned whether the degree of chemical drive, when measured during wakefulness, correlates with nocturnal ventilatory pattern generation and occasionally oxygen desaturation. In chronic obstructive pulmonary disease (COPD) patients, a low HCVR during wakefulness predisposes to oxygen desaturation during sleep [23]. The relation between chemical drive and sleep apnoea is less obvious.

Occasionally, depressed hypoxic drive has been associated with the occurrence of obstructive sleep apnoea [24]. In a patient with blunted HVR, no apnoeic events were observed during more than $4 \mathrm{~h}$ of sleep [25]. We studied five patients with severe chronic bronchitis and emphysema, who had undergone bilateral carotid body resection, during sleep and wakefulness. During all sleep studies neither central nor obstructive apnoeas were observed. There were, as a mean, 20 awakenings $\cdot$ night $^{-1}$ but they never occurred consecutively with an apnoeic 
event [26]. Therefore, it is more likely that, in humans, blunted chemoreflexes tend to stabilize the breathing pattern, although in some patients decreased hypoxic sensitivity may lead to instability of the upper airway, presumably due to depressed motoneuron output to the hypoglossal nerve [15].

Clinical studies looking at the effect of increased chemical drives on pattern generation are intriguing. Normal men, with relatively high ventilatory responses to hypoxia and hypercapnia, exhibit oscillations in ventilation during sleep [27]. The increase in inspiratory minute ventilation, following inspiratory airway obstruction during sleep, is significantly correlated with the HCVR measured preceding and following the obstructed inspirations [28].

Recently, we compared 14 normocapnic OSA patients, 11 chronic hypercapnic OSA patients and 11 patients with overlap syndrome (airflow limitation and OSA) with 14 heavy snorers and 14 controls, for their ventilatory response to $\mathrm{CO}_{2}$. A significant increase in the slope of the HCVR was found in the normocapnic OSA patients and in those with the overlap syndrome [29]. We hypothesized that the increased HCVR contributed to the instability in the breathing pattern and, therefore, indirectly to the occurrence of the OSA syndrome. This was not confirmed in another study looking at 35 nonhypercapnic sleep apnoea patients; it should be said, however, that in this study the values of the control group were relatively high [30]. Differences in the control group may account for many conflicting data in this area. More general agreement exists about the decreased HCVR in hypercapnic obstructive sleep apnoea-hypopnoea patients $[29,31]$. Recently, increased HCVR was also observed in patients with acromegaly and central sleep apnoea [32].

The role of the HVR in determining respiratory pattern may be more complex. A well performed study in 12 normal subjects indicated that the initial rapid increase in minute ventilation after mild hypoxia during sleep, correlated with the respective values of HVR during the awake state, but the final and lowered levels did not. It was concluded that the HVR during sleep is also biphasic, and hypoxic depression exerts considerable influence on ventilation during sleep [33]. However, in a study looking at 21 subjects with sleep apnoea, hypoxic ventilatory drive correlated with sleep desaturation [34].

We should also realize that respiratory drive can change from breath-to-breath and that many pharmacological agents can influence the degree of chemical drive. The rhythm-generating function of the respiratory control system seems to be more constant in healthy subjects than the drive component of the system [35]. The hypoxic ventilatory depression, also present during sleep [33], is attenuated by administration of aminophylline. This was demonstrated in 10 young adults, studied during wakefulness. Therefore, adenosine, which is blocked by aminophylline, may play a crucial role in the hypoxic ventilatory depression $[36,37] . \mathrm{CO}_{2}$ sensitivity also changes in accordance with the menstrual cycle. There is a significant increase in $\mathrm{CO}_{2}$ sensitivity between the follicular and luteal phases, which is attributed to progesterone [38].
The respiratory effect of progestin was also demonstrated in healthy men, in whom chlormadinone acetate caused a significant reduction in arterial $\mathrm{CO}_{2}$ tension $[39,40]$. On the other hand, administration of opiate drugs depresses ventilation and chemosensitivity. A natural rise in beta-endorphin, as expected to occur with marathon running, does not however modulate central chemosensitivity [41].

\section{$\mathrm{CO}_{2}$ threshold}

Effective ventilatory rhythmogenesis, in the absence of stimuli associated with wakefulness, seems to be critically dependent on chemoreceptor stimulation. Clinical studies looking at the influence of different levels of chemical drive on the pattern generation during sleep, have been summarized above. It was, however, more specifically recognized that during NREM sleep, central apnoea can occur after hyperventilation, when arterial carbon dioxide tension $\left(\mathrm{Pa}_{\left.\mathrm{a}, \mathrm{CO}_{2}\right)}\right)$ drops below a critical level, the so-called apnoeic threshold, usually located below $4.7 \mathrm{kPa}(35 \mathrm{mmHg})$ [42]. Subjects seem to be protected from developing this type of central apnoea by a preceding increase in end-tidal carbon dioxide tension $\left(P \mathrm{ET}, \mathrm{CO}_{2}\right)$, often occurring at sleep onset [43]. A sleepinduced increase in upper airway resistance, in the absence of immediate load compensation, seems to be an important determinant of $\mathrm{CO}_{2}$ retention [44]. The changes in upper airway resistance, observed in normal subjects, may be quite variable [45]. The higher the $\mathrm{CO}_{2}$ apnoeic threshold, the more central apnoeas will occur during sleep. The significance of the $\mathrm{CO}_{2}$ threshold was best illustrated during breathing at high altitude, where chronic hyperventilation (due to the acclimatization process) causes $P$ a, $\mathrm{CO}_{2}$ to be low and to drop below the threshold. This leads to periodic breathing and central sleep apnoea [46]. Recently, some methods were proposed to measure the $\mathrm{CO}_{2}$ threshold in conscious men [47]. Venous $\mathrm{CO}_{2}$ unloading in conscious humans can also lead to irregular breathing and central apnoeas [48, 49].

\section{Stage effects}

The apnoeic threshold for $\mathrm{CO}_{2}$ can be different during REM sleep compared to NREM. In dogs, during REM sleep, central apnoeas occur after brief hypoxic hyperventilation but there is no systematic relationship with the magnitude of the hypocapnia or the increase in tidal volume. In REM sleep (both phasic and tonic) a posthyperventilation apnoeic threshold seems not to be present [50]. These data are consistent with the finding that central sleep apnoea and periodic breathing is seldom seen during REM sleep. There may be also differences in ventilatory control between phasic and tonic REM. In normal men, ventilation, tidal volume and mean inspiratory flow are significantly decreased, whereas respiratory frequency is increased during phasic REM, when compared to tonic REM and NREM sleep [51]. Respiratory instability is most pronounced during sleep onset. In a study looking at 21 normal subjects, transition from alpha 
to theta activity was associated with a fall in ventilation, whereas transition from theta to alpha was related to an increase in ventilation. The magnitude of the observed changes was determined by the metabolic drive at the time of the state change (reflected by changes in alveolar carbon dioxide and oxygen tension $\left(\mathrm{P}_{\mathrm{A}, \mathrm{CO}_{2}}\right.$ and $\left.\mathrm{PA}_{\mathrm{A}, \mathrm{O}_{2}}\right)$ [52]. The increased instability in the breathing pattern during sleep onset is reflected by an increased number of apnoeas, and also by more snoring during stage 1 and 2 sleep [53]. We were also able to demonstrate that apnoeas occur more frequently during the drowsiness phase [54]. Many episodes of periodic breathing and central apnoea are triggered by hyperventilation, which leads to a reduction of $\mathrm{Pa}_{\mathrm{a}} \mathrm{CO}_{2}$ below the apnoeic threshold. Arousal can trigger hyperventilation and, therefore, aggravate and continue the process of unstable breathing. In a recent study, all episodes of periodic breathing were triggered by hyperventilation. Minute ventilation during the ventilatory phase of periodic breathing increased progressively, with increasing grades of associated arousals: lowest ventilation if no arousal occurred, intermediate values for electroencephalographic (EEG) arousal and highest values for movement arousal. Correspondingly, the length of the central apnoea also increased from no arousal to EEG arousal and movement arousal [55]. There is no doubt that arousal and hyperventilation can interact to trigger central sleep apnoea.

It has long been recognized that sleep deprivation selectively decreases genioglossal electromyographic (EMG) activity, during $\mathrm{CO}_{2}$ rebreathing in awake older subjects [56]. Therefore, sleep deprivation can play a role in the pathogenesis of obstructive sleep apnoea. But sleep deprivation can also aggravate the normally occurring periodic depressions in ventilation during phasic REM sleep, at least when studied in some animal models [57]. One could hypothesize that treatment strategies for central sleep apnoea could benefit from the interruption of sleep deprivation by eliminating the possible ventilatory depressant effects of sleep fragmentation brought about by the apnoea itself.

\section{Effects of lung volume}

Pharyngeal cross-sectional area decreases when functional residual capacity (FRC) is reduced, and oxygen saturation may also be volume-dependent. The influence of lung volume on apnoea duration was recently studied. Obstructive sleep apnoea tended to be longer when lung volume was increased, whereas the length of the central apnoeas was unchanged or even slightly decreased. Oxygen saturation, however, improves with increasing lung volume, even if the duration of the obstructive apnoeas is increased [58]. This phenomenon has to be taken into account when looking at the effects of treatment strategies (mainly nasal ventilation) that can have an influence on lung volume.

\section{Upper airway reflexes}

The role of afferents coming from the upper airway in determining the breathing pattern is illustrated by studies looking at the effect of nasal obstruction. During nasal obstruction, time spent in deep sleep stages decreased. This loss of deep sleep is associated with a twofold increase in arousals and awakenings due to an increase in apnoeas, mainly central and mixed [59]. Water instilled into the pharynx of sleeping human infants elicits a range of chemoreflex responses, including prolonged apnoeas. The occurrence of prolonged apnoea was greater after pharyngeal than nasal stimulation, and was frequently associated with coughing. The sensory site for eliciting these apnoeas is, therefore, probably close to the one mediating cough [60].

The effects of nasal obstruction on breathing during sleep may also be mediated by a reduction in $\mathrm{PCO}_{2}$. Six male volunteers were examined when asleep during noseopen and nose-obstructed conditions. $P \mathrm{ET}, \mathrm{CO}_{2}$ during nose-obstructed sleep was lower than that during noseopen sleep [61].

In animal studies, a number of upper airway reflexes have been described, including sniff-like aspiration reflexes and gasping [62]. The timing of the stimulus may be crucial. Activation at the postinspiratory phase may inhibit respiration [63]. Also, the type of stimulus may be crucial. Whether it may be possible in humans to elucidate "favourable" laryngeal reflexes remains controversial [64]. Sleep in itself may interfere with some upper airway reflexes. NREM sleep attenuates reflex genioglossus muscle activation by stimuli of negative airway pressure. Therefore, sleep may impair the ability of the upper airway to defend itself from suction collapse [65].

\section{Control system instability}

All the above-mentioned factors can be integrated into a global model. Also, some mathematical models have been developed, taking into account all the factors influencing breathing pattern generation. The occurrence of unstable breathing and periodic breathing depends on the quantitative relationships among the elements of the control systems and certain crucial parameters, such as controller gains, set points and circulation time. Prolongation of the information transfer, due to lengthened circulation time, and increased controller gains and set points make periodic breathing more likely to occur. Occasionally, the disturbance is sufficiently great to produce continuous periodic breathing, but more often periodic breathing and the occurrence of central apnoeas is transient. The number and the length of the apnoeas is an indication of the tendency for instability of the system [66]. It is obvious that the above described increase in chemical drive will contribute to the gain of the system. There are, however, still other factors involved. Metabolic rate can affect the stability of the response of the system: lower metabolic rates result in increases in the number of apnoeic cycles, when the system is disturbed. Also, a shift in the controller operating point during sleep with an increase in $\mathrm{Pa}_{\mathrm{a}} \mathrm{CO}_{2}$ can enhance the instability. Gas store changes are accelerated by the proportionally higher amount of $\mathrm{CO}_{2}$ expelled at a given ventilation rate when $\mathrm{Pa}_{\mathrm{a}} \mathrm{CO}_{2}$ is higher. In fact, during sleep, metabolic 
rate declines and $\mathrm{Pa}_{\mathrm{a}} \mathrm{CO}_{2}$ rises, whilst chemoreceptor gains decline as mentioned above, but their intersubject variability may be high. It is the interaction between all these factors that finally determines the breathing pattern. During light sleep, the overall result is mainly an increase in overall gain, whereas during slow wave sleep, due to a further decline in chemoreceptor gain, the overall gain declines. This explains, as mentioned earlier, that the most unstable breathing patterns are observed immediately when falling asleep and especially during drowsiness.

Periodic breathing can be simulated by mathematical models. They include the effect of chemical stimuli during sleep both on chest wall and upper airway muscle activity [67]. These models indicate that obstructive as well as central apnoeas can be due to control system instability. Central apnoeas increase the likelihood of obstructive apnoeas, whereas obstructive apnoeas tend to aggravate the control instability [68]. The interaction between central and obstructive apnoeas is, therefore, very likely and confirmed by many clinical observations.

\section{Interaction between central and obstructive sleep apnoea}

In order to study the relationship between sleep-induced periodic breathing and the development of occlusive sleep apnoeas, patients with hypersomnia-sleep apnoea were studied [69]. In this important study, it was shown that sleep-induced periodic breathing, representing the instability of the system, is primary to the development of occlusive sleep apnoeas. More recently, the relationship between periodic breathing and obstructive sleep apnoea was confirmed. The obstruction is, however, only manifested in subjects susceptible to upper airway atonicity and narrowing [70]. A cause and effect relationship between central and obstructive apnoeas is given by the (frequent) occurrence of mixed apnoeas, characterized by a period of decreased central drive followed by an obstructed breath. It is our experience that central apnoeas without subsequent obstruction are less frequent than mixed apnoeas, in a general referral population with suspicion of sleep-related breathing disorders. A high index for central apnoeas, with a low index for obstructive apnoeas, is encountered in only a limited number of subjects [9]. This probably reflects the large scatter in upper airway collapsibility and the tendency to collapse in most (even healthy) subjects [71] when the drive to the inspiratory muscles, and especially the upper airway muscles, is reduced at the nadir of periodic breathing. Upper airway muscle activation due to increasing $\mathrm{Pa}_{\mathrm{a}, \mathrm{CO}_{2}}$ may come behind the activation of the chest wall muscles. This represents an obvious cause of upper airway collapse [68]. During unstable breathing with waxing and waning of respiration, continuous changes in $\mathrm{Pa}, \mathrm{CO}_{2}$ may trigger obstructive breaths by this particular type of mechanism.

The decreased upper airway activation does not necess-arily lead to complete collapse. It was shown in normal volunteers that total pulmonary resistance may be at its highest at the nadir of periodic changes (induced by breathing hypoxic mixtures) without complete collapse of the upper airway [72]. There was also a significant linear relationship between resistance and $1 / V_{\mathrm{T}}$ (tidal volume). Therefore, obstructive hypopnoeas may also be triggered by periodic breathing. The same correlation between upper airway collapse and breathing pattern was studied in 10 healthy preterm infants in whom periodic breathing frequently occurs. Pulmonary resistance at half-maximal tidal volume, inspiratory time, expiratory time and mean inspiratory flow were derived from computer analysis of five cycles of periodic breathing. In $80 \%$ of infants, periodic breathing was accompanied by completely obstructed breaths at the onset of ventilatory cycles. The site of obstruction was located within the pharynx [73].

Some authors have concluded that the collapsibility of the upper airway in itself triggers irregularities in the breathing pattern and central apnoeas. Eight patients with idiopathic central sleep apnoea were compared to eight weight-matched, snoring control subjects. Patients with central apnoea, when compared with control subjects, exhibited markedly increased specific pharyngeal "compliance", increased change in pharyngeal area from FRC to residual volume (RV) and a larger pharyngeal area at FRC. It was, therefore, concluded that increased pharyngeal compliance and lung volume dependence may play a role in the aetiology of central apnoeas [74]. The number of patients studied was small, taking into account the large scatter in upper airway collapsibility in "normal" subjects [71]. However, it remains a very attractive hypothesis to suppose a relationship between upper airway mucosal stimulation during (near) collapse and the occurrence of central apnoea.

It was also shown that genioglossus muscle responds to negative airway pressure by reflex activation during wakefulness [75]. This reflex activation is reduced or lost during NREM sleep [76]. However, based on this data, one could speculate that decreased ventilation, as occurs during periodic breathing, goes along with less stimulation of the genioglossal muscle since the corresponding negative pressure stimulus is equally less.

Elderly people, with oscillations in upper airway resistance, have more apnoeas and hypopnoeas than those subjects without such oscillations. The oscillations in upper airway resistance produce a fluctuating mechanical limitation of ventilation, which may contribute to periodic breathing [77]. Another factor, that may prevent occlusive breaths due to instability in the breathing pattern, is the short-term poststimulus potentiation, or after-discharge, following a brief hypoxic stimulus. Afterdischarge in this circumstance prevents ventilation dropping below baseline, when hyperoxia and hypocapnia follow the hyperventilation phase, induced by the initial hypoxia. It was observed that patients with obstructive sleep apnoea have reduced after-discharge and, therefore, are prone to more unstable breathing [78].

\section{Clinical presentation}

Studies looking at the clinical presentation of central sleep apnoea are remarkably few in number. The clinical 
picture can be deduced from the pathogenetic mechanisms. Central apnoeas can occur in patients with reduced central drive. These patients mostly remain hypercapnic during wakefulness. The decline in central drive can be secondary to lesions in the brainstem, such as infections, infarction and tumour. Another group of patients in which central apnoeas occur are those with respiratory muscle weakness, as can be seen with neuromyopathies, myotonic dystrophy, muscular dystrophy, myasthenia gravis, amyotrophic lateral sclerosis, acid maltase deficiency, postpolio and diaphragmatic paralysis. In both groups, ventilation progressively decreases during sleep until the occurrence of apnoea. After disappearance of the wakefulness drive, breathing during sleep in these patients becomes completely dependent on a defective metabolic respiratory control system or on weakened respiratory muscles. These patients have a history of recurrent episodes of respiratory failure. They can present with polycythaemia or cor pulmonale. When respiratory neuromuscular disease is present, weakness of the extremities usually also exists. Men and women are equally affected. Snoring and morning headaches are common but nasal obstruction, hypertension and nocturnal awakenings are uncommon. Daytime sleepiness often occurs [79, 80].

Most of the patients with central sleep apnoea, however, have preserved chemical drive and normal respiratory muscle function. The occurrence of the central apnoeas is part of an overall instability in the breathing pattern brought about by all the mechanisms, described above, that can increase the overall gain of the respiratory controller. This can occur in well-described diseases, such as chronic heart failure; mostly, however, no underlying disorder is recognized. These patients with recurrent central apnoeas will have sleep fragmentation due to arousals and, therefore, many of the daytime clinical symptoms are similar to those observed in obstructive sleep apnoea. As already discussed, many patients have both types of apnoea. Patients report snoring, daytime sleepiness and, sometimes, nasal obstruction and hypertension. There seems to be a male preponderance. Since this type of central sleep apnoea is not associated with severe hypoxaemia, polycythaemia or cor pulmonale is not observed [79]. It is, however, not well established that these patients have completely normal gas exchange. We were impressed by the improvement in $\mathrm{Pa}_{\mathrm{a}, \mathrm{CO}_{2}}$ that could be obtained by treating central apnoea patients with acetazolamide for a longer time period. All these patients were normocapnic and had preserved $\mathrm{CO}_{2}$ drive [9]. Therefore, it may well be, that some degree of ventilation/perfusion $\left(V^{\prime} / Q^{\prime}\right)$ mismatch is a part of the clinical picture as well.

Central sleep apnoea is reported to be less common than obstructive apnoea. It was suggested that central apnoea occurs at $10 \%$ the rate of obstructive sleep apnoea [79]. In another study, home sleep recordings were performed in 358 randomly selected elderly volunteers (mean age $72 \mathrm{yrs}$ ). Seventeen percent had predominantly obstructive apnoeas, $6 \%$ predominantly central apnoeas and in $1 \%$ mixed apnoeas were observed [81]. We observed predominantly central sleep apnoea in 14 out of 327 patients
(4\%) referred with suspicion of sleep-related breathing disorders [9]. Our overall impression is that central apnoea is far more common than generally accepted until now, especially when mixed apnoeas are also taken into account. However, it remains unclear to what extent the central apnoea syndrome contributes to the reported symptoms of daytime sleepiness [2, 3].

Central apnoeas cause daytime sleepiness by provoking arousal and sleep fragmentation comparable to obstructive apnoeas. The cardiovascular consequences of central and obstructive apnoeas can, however, be different, as was reported in a recent animal study. In 12 anaesthetized dogs, obstructive and central apnoeas were induced. During both types of apnoea, changes in $\mathrm{Pa}, \mathrm{O}_{2}$ and $P \mathrm{a}, \mathrm{CO}_{2}$ were approximately the same. During obstructive apnoeas, mean blood pressure and cardiac output did not change significantly. During central apnoea, blood pressure did not change but cardiac output decreased by far more than with obstructive apnoea. This may be due to a lack of respiratory mechanoreceptor input during central apnoea. The authors concluded that the cardiac dysfunction with central apnoea could lead to pulmonary vascular congestion [82]. Whether this also applies to humans remains uncertain, but it has been reported that increased ventilation attenuates the sympathetic activation in response to hypoxia or hypercapnia [83].

Mortality due to obstructive sleep apnoea is well described. The probability of cumulative 8-year survival was 0.96 for patients with an apnoea index $(\mathrm{AI})<20$ and 0.63 for those with an AI $>20$. Difference in mortality related to AI was particularly true in patients less than 50 yrs of age, in whom mortality from other causes is uncommon [84]. The impact of central sleep apnoea with and without Cheyne-Stokes respiration (CSR) on morbidity and mortality was recently studied; 108 patients were followed up to determine survival rates. Fifty nine patients died, all but five due to a cardiac or pulmonary problem. Thirty one patients without apnoeas had a mean survival time of 1,354 days, those with central apnoea and mild CSR 1,533 days, but those with severe CSR had a mean survival of only 855 days. Of this group, $87 \%$ died compared to $45 \%$ in the group of subjects without apnoeas [85]. Therefore, patients with the most unstable breathing seem to have the shortest survival. However, it could not be proved that CSR was an independent predictor of the elevated mortality risk.

\section{Treatment}

There is little consensus at present about the treatment of patients with central sleep apnoeas, especially those with preserved central drive. In many chronic hypercapnic patients, artificial nasal ventilation becomes increasingly the treatment of choice.

\section{Hypercapnic patients}

Intermittent negative or positive pressure ventilation at night was applied to patients with chronic hypercapnic 
respiratory failure caused by many different aetiologies, including neuromuscular diseases and chronic airway disease. Negative pressure ventilation is uncomfortable and can cause upper airway obstruction. Increase in oxygen tension and fall in carbon dioxide tension can be produced, however, with nasal intermittent positive pressure ventilation. In chronic hypercapnic COPD patients, small but significant changes in daytime blood gases occurred in those using nocturnal ventilation. Residual volume tended to fall, whilst ventilatory response to hypercapnia increased after nasal ventilation [86, 87]. Improvement in $\mathrm{CO}_{2}$ drive was also shown after continuous positive airway pressure (CPAP) therapy, in patients with obstructive sleep apnoea and hypercapnia [88, 89]. In normocapnic patients, the effects of CPAP on chemical drive are limited, with a tendency to decrease the hypercapnic ventilatory response [90]. Also, in patients with acute respiratory failure nasal ventilation can be used successfully, whether to wean the patients [91] or to avoid endotracheal intubation [92, 93]. In these studies, however, there is never a careful analysis of the effect of nasal ventilation on the occurrence of central apnoeas.

Respiratory stimulants have been shown to be effective in this group of patients. They have been studied mainly in patients with chronic respiratory failure due to obstructive airway disease. Among them, progestin [39, 40] and almitrine have been shown to be of particular interest. A persistent improvement, after 2 yrs treatment, in $P \mathrm{a}, \mathrm{O}_{2}$ and $\mathrm{Pa}_{\mathrm{a}, \mathrm{CO}_{2}}$ was demonstrated for almitrine in eighty nine patients with hypoxic chronic obstructive airways disease [94]. Almitrine bismesylate is, however, a peripheral chemoreceptor agonist [95] and will, therefore, increase the overall gain of the controller system. Although almitrine may be very useful in hypercapnic patients with respiratory insufficiency, it can be anticipated that its use in nonhypercapnic central apnoea patients would aggravate the instability in the breathing pattern, unless the increase in $\mathrm{Pa}_{\mathrm{a}} \mathrm{O}_{2}$ would offset this effect.

The use of supplemental oxygen was studied in a patient with primary alveolar hypoventilation (and chronic hypercapnia) with central sleep apnoea. After institution of low-flow nocturnal oxygen, there was a marked decrease in the number and duration of sleep apnoeas and an increase in the level of ventilation during sleep. Since the patient had no demonstrable ventilatory response to hypoxia during wakefulness, the effect of oxygen during sleep might have been due to the elevation of hypoxic brainstem depression [96].

\section{Normocapnic patients}

Low-flow oxygen decreases the frequency of the three types of apnoea (central, mixed and obstructive). In 12 patients with predominantly obstructive sleep apnoea, $6 \mathrm{~h}$ of continuous low-flow oxygen $\left(3 \mathrm{~L} \cdot \mathrm{min}^{-1}\right)$ induced a significant reduction in the percentage of central and mixed sleep-disordered breathing events, with a corresponding increase in the percentage of obstructive sleep-disordered breathing events [97]. In nine patients with predominantly central and mixed apnoeas, oxygen reduced the overall apnoea frequency from 66 to 43 episodes $\cdot$ hour $^{-1}$ whereas the central and mixed apnoeas decreased markedly from 31.4 to 6.4 and from 20.9 to 4.9 episodes $\cdot$ hour $^{-1}$ respectively. Obstructive apnoea frequency more then doubled from 13.9 to 32.1 episodes $\cdot$ hour $^{-1}$ [98]. Therefore, if oxygen is used to stabilize the breathing pattern in patients with predominantly central apnoeas, a control polysomnography during oxygen administration is warranted. The use of oxygen in patients with obstructive apnoeas remains even more controversial [99]. There seems to be no improvement in daytime hypersomnolence, although the overall time spent in apnoea may be somewhat less.

In a patient treated for obstructive sleep apnoea with tracheostomy, the relief of upper airway obstruction unmasked severe central sleep apnoea. This patient was treated successfully with supplemental $\mathrm{CO}_{2}$ therapy [100]. This case report illustrates many fundamental aspects of the problem of central sleep apnoea. It illustrates the interaction between central and obstructive apnoeas and the crucial role of the $\mathrm{CO}_{2}$ threshold in the pathogenesis. Although of great theoretical interest, the treatment of patients with inhaled $\mathrm{CO}_{2}$ is not practical. Therefore, many other therapeutic options have been studied.

Since arousal may aggravate the syndrome, the use of sleep medication could, theoretically, be of potential interest. There are at present no long-term studies available to illustrate whether this theoretical concept is of practical value. Triazolam was evaluated in normal subjects that were aroused by occluding a mask, covering the nose with the mouth sealed. In this study, the time to arousal was significantly longer on triazolam nights. Also, the maximal airway suction pressure preceding arousal was higher on triazolam nights [101]. In a preliminary study, we observed some improvement in the periodic breathing pattern at high altitude after administration of triazolam [102]. More studies are needed to establish the role of drugs interacting with arousal in the treatment of central apnoea.

In five patients with Cheyne-Stokes respiration (CSR), comprising $47-86 \%$ of all disordered-breathing events, the effects of theophylline were studied. Theophylline significantly decreased CSR. Lowest $\mathrm{O}_{2}$ saturation associated with CSR improved. Also, the disruption in sleep architecture improved significantly with therapy [103]. These data are somewhat surprising since theophylline may abolish hypoxic ventilatory depression and therefore predispose to more unstable breathing [33, 36, 37]. Clearly, more patients should be studied to establish the role of theophylline in treating patients with central sleep apnoea.

Acetazolamide was studied initially in six patients with symptomatic central sleep apnoea. Sleep studies were carried out before and after one week of drug therapy, using $250 \mathrm{mg}$ orally q.i.d. All six patients had a significant improvement, demonstrating a $69 \%$ reduction in total apnoeas. Due to the relative high dose of acetazolamide, $\mathrm{pH}$ dropped substantially from 7.42 to 7.34 [104]. In another study looking at nine patients with predominately obstructive apnoeas, $250 \mathrm{mg}$ acetazolamide administered daily reduced the apnoea index and the total 
duration of apnoea. There was no conversion from obstructive apnoeas to the central type, or vice versa [105]. More recently, we looked at the effects of acetazolamide in symptomatic patients with predominantly central sleep apnoea. The aim of this study was to treat selected central apnoea patients with low dose acetazolamide $\left(250 \mathrm{mg} \cdot\right.$ day $\left.^{-1}\right)$ for a longer time period ( $\left.1 \mathrm{month}\right)$. Patients were selected if their central apnoea index was $>5$ or their apnoea-hypopnoea index $>10$ and their obstructive apnoea index $<5$. Fourteen patients fulfilled this criteria. Polysomnography was repeated once after one single dose (N2) and twice after 1 month of chronic treatment without (N3) and with (N4) additional acetazolamide treatment. Central apnoea index (25.5 at N1) decreased during N2 (13.8) and further decreased during N3 (6.6) and N4 (6.8). The obstructive apnoea index remained unchanged. All patients subjectively improved, with fewer complaints of hypersomnolence, falling asleep during the day, memory losses and tiredness in the morning. $P \mathrm{a}, \mathrm{O}_{2}$ improved from $10.3 \mathrm{kPa}(77 \mathrm{mmHg})$ at $\mathrm{N} 1$ to $12.1 \mathrm{kPa}(91 \mathrm{mmHg})$ at $\mathrm{N} 3$; $\mathrm{pH}$ only dropped from 7.41 to 7.38. We concluded, therefore, that chronic therapy with low dose acetazolamide in patients with nonhypercapnic central sleep apnoea improves the breathing pattern and the pulmonary gas exchange [9]. Since this initial study, we followed these patients for an even longer time period. Interruption of therapy after 4 months treatment was not followed by an immediate recurrence of symptoms or an increase in the apnoea index [106]. We believe that acetazolamide, initially used to treat and prevent acute mountain sickness, can be very useful and effective in treating patients with central apnoea with preserved chemical drives. Initially, the action of acetazolamide was ascribed to the induced metabolic acidosis. It is, however, likely that acetazolamide may also act by other mechanisms. Different effects of carbonic anhydrase inhibition on the hypercapnic and hypoxic ventilatory responses between acute administration of acetazolamide (only associated with local tissue changes in $\mathrm{pH}$ ) and chronic acetazolamide administration (associated also with changes in systemic $\mathrm{pH}$ ) indicate that acetazolamide can act not only by changes in systemic acidbase balance, but also by direct effect on chemoreceptors [107, 108]. In animal studies, it was also shown that acetazolamide causes a decrease in activity of the peripheral chemoreceptors and also a decrease of their sensitivity to $P \mathrm{a}, \mathrm{O}_{2}$ changes [109]. If this also applied to men, it can easily be understood that acetazolamide can stabilize breathing by this mechanism. It was also demonstrated in the rat that acetazolamide significantly increases blood flow in the cortical, thalamic and pontine regions [110]. How this relates to the observed effect on breathing pattern generation still remains to be determined.

The potential use of nasal CPAP for the treatment of central sleep apnoea was illustrated in a study of eight patients with predominantly central sleep apnoea. High levels of CPAP (range 9-16.5 $\mathrm{cmH}_{2} \mathrm{O}$ ) prevented all central apnoeas and mixed apnoeas and resulted in quiet breathing in all patients. Intermediate levels of CPAP produced firstly mixed apnoeas, then purely obstructive apnoeas and/or continuous snoring. Based on these data, the authors concluded that upper airway collapse in the supine posture has a key role in the induction of central apnoeas [111]. In a more recent study, it was shown, however, that short-term treatment with nasal CPAP in patients with chronic heart failure does not improve either Cheyne-Stokes respiration, nocturnal oxygenation or sleep quality [112]. Taking into account the current controversies, one should carefully weigh the potential benefit of this therapy against the substantial burden of nasal CPAP to the patients. Although CPAP therapy has been reported to be successful in some patients [113], it can probably not be seen as a generally acceptable treatment modality for patients with central sleep apnoea. One can, however, try to develop other similar treatment modalities, making use of upper airway mucosal stimulation.

The effects of high-frequency $(30 \mathrm{~Hz})$ low-pressure oscillations on respiration in nine patients with central sleep apnoea were studied. High-frequency oscillations of the upper airway stimulated respiratory efforts in $68 \%$ of all trials. Apnoea length was significantly shortened in four of the nine patients. In one patient with a tracheostomy, the stimulus applied to his isolated upper airway evoked respiratory efforts during central apnoea in 13 of 15 trials. It was suggested that the response was mediated by upper airway receptors [114]. It may probably be possible, in the near future, to use these nonrespiratory reflexes to treat central sleep apnoea when adequate equipment can be developed, and application at a larger scale confirms these results. Electrical stimulation was mainly studied in obstructive sleep apnoea patients. In a recent study, looking at four healthy asymptomatic subjects and seven patients with obstructive apnoeas, it could be demonstrated that subjects tolerate surface and fine-wire functional electrical stimulation (with electrodes placed into the neurovascular bundle of the hypoglossal nerve) to a higher stimulus during sleep than during wakefulness. Both approaches, however, have an inconsistent effect on apnoeas during sleep [115]. It may be interesting to apply the same methods to patients with central apnoeas.

\section{Central apnoea and congestive heart failure}

Ventilatory instability in patients with congestive heart failure $(\mathrm{CHF})$ has been studied in more detail. Patients with CHF (left ventricular ejection fraction (9-48\%) who demonstrated Cheyne-Stokes respiration only while asleep, were studied during wakefulness. The test involved brief (30-50 s) exposure to hypoxia, followed by breathing pure oxygen. Nine patients were compared to 13 agematched normals. During hypoxia, ventilation increased similarly in both groups. During hyperoxia, breathing patterns differed between the groups. In normals, ventilation gradually declines during hyperoxia but does not drop below baseline ventilation. In patients, ventilation drops below baseline, being at $72 \%$ of air-breathing control at $45 \mathrm{~s}$ of hyperoxia. These results in patients are compatible with the absence of short-term potentiation activated by hypoxic hyperventilation [116]. This is one 
of the possible mechanisms that can explain the breathing instability in CHF patients. It has been suggested, however, that fluctuations in pulmonary blood flow are primarily responsible for the periodic breathing in CHF [117]. In 24 male patients with $\mathrm{CHF}$ it was demonstrated that the awake $P \mathrm{a}, \mathrm{CO}_{2}$ and mean sleep transcutaneous $P_{\mathrm{CO}_{2}}\left(\mathrm{Pt}_{\mathrm{t}, \mathrm{CO}_{2}}\right)$ were significantly lower in those with Cheyne-Stokes respiration and central apnoea (CSRCSA), compared to those without CSR-CSA. CSR-CSA cycle length correlated with lung to ear circulation time. Therefore, hypocapnia and circulatory delay may be equally important contributory factors [118]. Some authors have also demonstrated an increased ventilatory response to $\mathrm{CO}_{2}$ in patients with $\mathrm{CHF}$ [119]. Clearly, not only circulation delay, but abnormalities in chemoreceptor responses to hypoxia and hypercapnia may be involved in the pathogenesis of Cheyne-Stokes respiration in CHF. The treatment of these patients with nasal ventilation, as mentioned earlier, remains controversial [112].

In conclusion, patients with central sleep apnoea are mostly nonhypercapnic and without obvious disease. Their breathing instability during sleep can, however, lead to major symptoms, with hypersomnolence and tiredness. Many mechanisms can be involved, but most contribute to the increase in the overall gain of the controller system. Their relevance has been demonstrated in a large number of clinical studies. In contrast, few treatment strategies have been described. Some therapies (such as nasal ventilation and inhalation of $\mathrm{CO}_{2}$ ) can only be applied to a limited number of co-operative patients. Drug treatments, especially with acetazolamide, may be easier to perform. Their efficacy remains to be demonstrated when applied on a larger scale. Some recent applications of upper airway stimulation seems to be promising for the near future, given the amelioration of the techniques.

\section{References}

1. Klink M, Quan SF. Prevalence of reported sleep disturbances in a general adult population and their relationship to obstructive airways diseases. Chest 1987; 91(4): 540-546.

2. Janson C, Gislason T, De Backer W, et al. Daytime sleepiness, snoring and gastroesophageal reflux among young adults in three European countries. J Int Med 1995; (in press).

3. Janson C, Gislason T, De Backer W, et al. Prevalence of sleep disturbances among young adults in three European countries. Sleep 1995; (submitted).

4. Redline S, Kump K, Tishler P, Browner I, Ferrette V. Gender differences in sleep disordered breathing in a community-based sample. Am J Respir Crit Care Med 1994; 149: 722-726.

5. Partinen M, Telakivi T. Epidemiology of obstructive sleep apnoea syndrome. Sleep 1992; 15: S1-S4.

6. Stradling JR, Crosby JH. Predictors and prevalence of obstructive sleep apnoea and snoring in 1,001 middleaged men. Thorax 1991; 46: 85-90.

7. Ferini-Strambi L, Zucconi M, Palazzi S, et al. Snoring and nocturnal oxygen desaturations in an Italian middleaged male population. Chest 1994; 105(6): 1759-1764.
8. Young T, Palta M, Dempsey J, Skatrud J, Weber S, Badr S. The occurrence of sleep-disordered breathing among middle-aged adults. N Eng J Med 1993; 328: 1230-1235.

9. De Backer WA, Verbraecken J, Willemen M, Wittesaele W, De Cock W, Van de Heyning P. Central apnea index decreases after prolonged treatment with acetazolamide. Am J Respir Crit Care Med 1995; 151: 87-91.

10. Marcus CL, Omlin KJ, Basinki DJ, et al. Normal polysomnographic values for children and adolescents. Am Rev Respir Dis 1992; 146: 1235-1239.

11. Severinghaus JW, Mitchell RA. Ondine's curse-failure of respiratory centre automaticity while awake. Clin Res 1962; 10: 122.

12. Udwadia ZF, Athale S, Misra VP, Wadia NH. Radiation necrosis causing failure of automatic ventilation during sleep with central sleep apnea. Chest 1897; 92(3): 567569

13. Sato T, Tadokoro M, Kaba H, Saito H, Seto K, Takatsuji H. Centrally administered ouabain aggravates central sleep apneas. J Appl Physiol 1993; 74(2): 545-548.

14. Feldman JL, Smith JC. Neural control of respiratory pattern in mammals: an overview. In: Dempsey JA, Pack AI, eds. Regulation of Breathing. New York, Marcel Dekker, 1995; pp. 39-69.

15. Bruce E, Mitra J, Cherniack N. Central and peripheral chemoreceptor inputs to phrenic and hypoglossal motoneurons. J Appl Physiol: Respirat Environ Exercise Physiol 1982; 53(6): 1504-1511.

16. Marcus CL, Glomb WB, Basinski DJ, Ward SL, Keens TG. Developmental pattern of hypercapnic and hypoxic ventilatory responses from childhood to adulthood. $J$ Appl Physiol 1994; 76(1): 314-320.

17. Naifeh KH, Severinghaus JW, Kamiya J, Krafft M. Effect of aging on the estimates of hypercapnic ventilatory response during sleep. J Appl Physiol 1989; 66(4): 1956-1964.

18. Reed DJ, Kellogg RH. Effect of sleep on $\mathrm{CO}_{2}$ stimulation of breathing in acute and chronic hypoxia. J Appl Physiol 1960; 15(6): 1135-1138.

19. Reed DJ, Kellogg RH. Changes in respiratory response to $\mathrm{CO}_{2}$ during natural sleep at sea level and at altitude. J Appl Physiol 1958; 13(3): 325-330.

20. Douglas NJ, White DP, Weil JV, Pickett CK, Zwillich CW. Hypercapnic ventilatory response in sleeping adults. Am Rev Respir Dis 1982; 126: 758-762.

21. Douglas NJ, White DP, Weil JV, et al. Hypoxic ventilatory response decreases during sleep in normal men. Am Rev Respir Dis 1982; 125: 286-289.

22. Santiago TV, Scardella AT, Edelman NH. Determinants of the ventilatory responses to hypoxia during sleep. Am Rev Respir Dis 1984; 130: 179-182.

23. Fleetham JA, Mezon B, West P, Bradley CA, Anthonisen NR, Kryger MH. Chemical control of ventilation and sleep arterial oxygen desaturation in patients with COPD. Am Rev Respir Dis 1980; 122: 583-589.

24. Parisi RA, Croce SA, Edelman NH, Santiago TV. Obstructive sleep apnea following bilateral carotid body resection. Chest 1987; 91(6): 922-924.

25. Eichenhorn MS, Dossantos CJ, Harper PA. Abnormal breathholding in association with carotid body dysfunction mimicking sleep apnea. Am Rev Respir Dis 1983; 128: 765-767.

26. De Backer WA. Ventilation and breathing pattern in man during sleep and wakefulness after bilateral carotid body resection. In: Studies on the Chemical Regulation of Breathing in Man. PhD Thesis, University of Antwerp, 1988; pp. 97-105. 
27. Chapman KR, Bruce EN, Gothe B, Cherniack NS. Possible mechanisms of periodic breathing during sleep. J Appl Physiol 1988; 64: 1000-1008.

28. Gleeson K, Zwillich CW, White DP. Chemosensitivity and the ventilatory response to airflow obstruction during sleep. J Appl Physiol 1989; 67(4): 1630-1637.

29. Verbraecken J, De Backer W, Willemen M, De Cock W, Wittesaele $\mathrm{W}$, Van de Heyning P. Chronic $\mathrm{CO}_{2}$ drive in patients with obstructive sleep apnea and effect of CPAP. Respir Physiol 1995; (in press).

30. Gold AR, Schwartz AR, Wise RA, Smith PL. Pulmonary function and respiratory chemosensitivity in moderately obese patients with sleep apnea. Chest 1993; 103: 1325-1329.

31. Javaheri S, Colangelo G, Lacey W, Gartside P. Chronic hypercapnia in obstructive sleep apnea-hypopnea syndrome. Sleep 1994; 17(5): 416-423.

32. Grunstein RR, Ho KY, Berthon-Jones M, Stewart D, Sullivan C. Central sleep apnea is associated with increased ventilatory response to carbon dioxide and hypersecretion of growth hormone in patients with acromegaly. Am J Respir Crit Care Med 1994; 150: 496-502.

33. Chin K, Ohi M, Hirai M, Kuriyama T, Sagawa Y, Kuno K. Breathing during sleep with mild hypoxia. J Appl Physiol 1989; 67(3): 1198-1207.

34. Kunitomo F, Kimura H, Tatsumi K, et al. Abnormal breathing during sleep and chemical control of breathing during wakefulness in patients with sleep apnea syndrome. Am Rev Respir Dis 1989; 139: 164-169.

35. Tobin MJ, Mador MJ, Guenther SM, Lodato RF, Sackner MA. Variability of resting respiratory drive and timing in healthy subjects. J Appl Physiol 1988; 65(1): 309-317.

36. Georgopoulos D, Holtby SG, Berezanski D, Anthonissen NR. Aminophylline effects on ventilatory response to hypoxia and hyperoxia in normal adults. $J$ Appl Physiol 1989; 67(3): 1150-1156.

37. Runold M, Lagercrantz H, Prabhakar NR, Fredholm BB Role of adenosine in hypoxic ventilatory depression. $J$ Appl Physiol 1989; 67(2): 541-546.

38. Dutton K, Blanksby BA, Morton AR. $\mathrm{CO}_{2}$ sensitivity changes during the menstrual cycle. J Appl Physiol 1989; 67(2): 517-522.

39. Mikami M, Tatsumi K, Kimura H, Honda Y, Kuriyama T. Respiration effect of synthetic progestin in small doses in normal men. Chest 1989; 96: 1073-1075.

40. Skatrud JB. Progestins and ventilatory stimulation. Chest 1989; 96(5): 969.

41. Mahler DA, Cunningham LN, Skrinar GS, Kraemer WJ, Colice GL. Beta-endorphin activity and hypercapnic ventilatory responsiveness after marathon running. J Appl Physiol 1989; 66(5): 2431-2436.

42. Skatrud J, Dempsey J. Interaction of sleep state and chemical stimuli in sustaining rhythmic ventilation. $J$ Appl Physiol: Respirat Environ Exercise Physiol 1983; 55: 813-822.

43. Skatrud J, Dempsey J. A sleep-induced apneic threshold and its consequences. Am Rev Respir Dis 1986; 133: $1163-1170$

44. Skatrud J, Dempsey J, Badr S, Begle R. Effect of airway impedance on $\mathrm{CO}_{2}$ retention and respiratory muscle activity during NREM sleep. J Appl Physiol 1988; 65: $1676-1685$

45. Wiegaard L, Zwillich CW, White DP. Collapsibility of the human upper airway during normal sleep. J Appl Physiol 1989; 66: 1800-1808.

46. West J, Peters R, Aksenes G, Maret K, Milledge J, Schoene R. Nocturnal periodic breathing at altitude of 6,300 and 8,050m. J Appl Physiol 1986; 61: 280287.

47. Cummin ARC, Sidhu VS, Telford RJ, Saunders KB. Ventilatory responsiveness to carbon dioxide below the normal control point in conscious normoxic humans. Eur Respir J 1992; 5: 512-516.

48. De Backer WA, Heyrman RM, Wittesaele WM, Van Waeleghem JP, Vermeire PA, De Broe ME. Ventilation and breathing patterns during hemodialysis-induced $\mathrm{CO}_{2}$ unloading. Am Rev Respir Dis 1987; 136: 406-410.

49. De Backer W. Clinical significance of studying resting $\mathrm{CO}_{2}$ drive after $\mathrm{CO}_{2}$ unloading. Eur Respir $J$ 1992; 5: 507-508.

50. Curtis LX, Saupe KW, Henderson KS, Dempsey JA. Effects of rapid-eye-movement sleep on the apneic threshold in dogs. J Appl Physiol 1993; 75(3): 1129-1139.

51. Wiegand L, Zwillich CW, Wiegand D, White DP. Changes in upper airway muscle activation and ventilation during phasic REM sleep in normal men. J Appl Physiol 1991; 71(2): 488-497.

52. Trinder J, Whitworth F, Kay A, Wilkin P. Respiratory instability during sleep onset. J Appl Physiol 1992; 73(6): 2462-2469.

53. Perez-Padilla J, West P, Kryger M. Snoring in normal young adults: prevalence in sleep stages and associated changes in oxygen saturation, heart rate and breathing pattern. Sleep 1987; 10: 249-253.

54. Verbraecken J, De Backer W, De Cock W, Wittesaele W, Van de Heyning P. The necessity of an alternative EEG scoring system in obstructive sleep apnea. Acta Oto Rhino Laryngol (Belg) 1994; 48: 27-35.

55. Xie A, Wong B, Phillipson EA, Slutsky AS, Bradley TD. Interaction of hyperventilation and arousal in the pathogenesis of idiopathic central sleep apnea. Am J Respir Crit Care Med 1994; 150: 489-495

56. Leiter JC, Knuth SL, Bartlett D. The effect of sleep deprivation on activity of the genioglossus muscle. Am Rev Respir Dis 1985; 132: 1242-1245.

57. Veasey SC, Hendricks JC, Kline LR, Pack AI. Effects of acute sleep deprivation on control of the diaphragm during REM sleep in cats. J Appl Physiol 1993; 74(5): 2253-2260.

58. Series F, Cormier Y, Lampron N, La Forge J. Influence of lung volume in sleep apnoea. Thorax 1989; 44: 52 57.

59. Zwillich CW, Pickett C, Hanson FN, Weil JV. Disturbed sleep and prolonged apnea during nasal obstruction in normal men. Am Rev Respir Dis 1981; 124: 158-160.

60. Davies AM, Koenig JS, Thach BT. Characteristics of upper airway chemoreflex prolonged apnea in human infants. Am Rev Respir Dis 1989; 139: 668-673.

61. Tanaka Y, Honda Y. Nasal obstruction as a cause of reduced $P_{\mathrm{CO}_{2}}$ and disordered breathing during sleep. $J \mathrm{Appl}$ Physiol 1989; 67(3): 970-972.

62. Tomori Z, Donic V, Kurpas M. Comparison of inspiratory effort in sniff-like aspiration reflex, gasping and normal breathing. Eur Respir J 1993; 1: 53-59.

63. Richter D, Ballantyne D. A three phase theory about the basic respiratory pattern generator. In: Schlafke M, Koepchen H, See W, eds. Central Neurone Environment. Berlin, Springer-Verlag, 1983; pp. 165-174.

64. De Backer W. Upper airway reflexes and obstructive sleep apnoea. Eur Respir J 1993; 6: 12-13.

65. Horner RL, Innes JA, Morrell MJ, Shea SA, Guz A. The effect of sleep on reflex genioglossus muscle activation by stimuli of negative airway pressure in humans. $J$ Physiol 1994; 476(1): 141-151. 
66. Cherniack NS, Longobardo GS. Effect of metabolic rate on the occurrence of periodic breathing. In: Issa FG, Suratt PM, Remmers JE, eds. Sleep and Respiration. Wiley-Liss. Inc. 1990; pp. 167-176.

67. Cherniack NS, Von Euler C, Homma I, Kao FF. Experimentally-induced Cheyne-Stokes breathing. Respir Physiol 1979; 37: 185-200.

68. Longobardo GS, Gothe B, Goldman MD, Cherniack NS. Sleep apnea considered as a control system instability. Respir Physiol 1982; 50: 311-333.

69. Önal E, Lopata M. Periodic breathing and the pathogenesis of occlusive sleep apneas. Am Rev Respir Dis 1982; 126: 676-680.

70. Warner G, Skatrud JB, Dempsey JA. Effect of hypoxiainduced periodic breathing on upper airway obstruction during sleep. J Appl Physiol 1987; 62(6): 2201-2211

71. Wiegand L, Zwillich CW, White DP. Collapsibility of the human upper airway during normal sleep. J Appl Physiol 1989; 66(4): 1800-1808.

72. Önal E, Burrows DL, Hart RH, Lopata M. Induction of periodic breathing during sleep causes upper airway obstruction in humans. J Appl Physiol 1986; 61(4): 1438-1443.

73. Miller MJ, Carlo WA, Difiore JM, Martin RJ. Airway obstruction during periodic breathing in premature infants. J Appl Physiol 1988; 64(6): 2496-2500.

74. Bradley TD, Brown IG, Zamel N, Phillipson EA, Hoffstein $\mathrm{V}$. Differences in pharyngeal properties between snorers with predominantly central sleep apnea and those without sleep apnea. Am Rev Respir Dis 1987; 135: 387-391.

75. Horner RL, Innes JA, Murphy K, Guz A. Evidence for reflex upper airway dilator muscle activation by sudden neg-ative airway pressure in man. J Physiol 1991; 436: $15-29$.

76. Wheatley JR, Mezzanotte WS, Tangel DJ, White DP. Influence of sleep on genioglossus muscle activation by negative pressure in normal men. Am Rev Respir Dis 1993; 148: 597-605.

77. Hudgel DW, Devadatta P, Hamilton H. Pattern of breathing and upper airway mechanics during wakefulness and sleep in healthy elderly humans. J Appl Physiol 1993; 74(5): 2198-2204.

78. Georgopoulus D, Giannouli E, Tsara V, Argiropoulou P. Respiratory short-term poststimulus potentiation (afterdischarge) in patients with obstructive sleep apnea. Am Rev Respir Dis 1992; 146: 1250-1255.

79. Bradley TD, Phillipson EA. Central sleep apnea. Clin Chest Med 1992; 13(3): 493-505.

80. Bradley TD, McNicholas WT, Rutherford R, Popkin J, Zamel N, Phillipson EA. Clinical and physiologic heterogeneity of the central sleep apnea syndrome. Am Rev Respir Dis 1986; 134: 217-221.

81. Ancoli-Israel S, Kripke DF, Mason W. Characteristics of obstructive and central sleep apnea in the elderly: an interim report. Biol Psychiatry 1987; 22: 741-750.

82. Tarasiuk A, Scharf SM. Cardiovascular effects of periodic obstructive and central apneas in dogs. Am J Respir Crit Care Med 1994; 150: 83-89.

83. Somers VK, Abboud FM. Chemoreflexes: responses, interactions and implications for sleep apnea. Sleep 1993; 16: S30-S34.

84. He J, Kryger MH, Zorick FJ, Conway W, Roth T. Mortality and apnea index in obstructive sleep apnea. Chest 1988; 94: 9-14.

85. Ancoli-Israel S, Engler RL, Friedman PJ, Klauber MR, Ross PA, Kripke DF. Comparison of patients with central sleep apnea. Chest 1994; 106: 780-786.
86. Calverley PM. Domiciliary ventilation in chronic obstructive lung disease. Thorax 1992; 47: 334-336.

87. Elliott MW, Simonds AK, Carroll MP, Wedzicha JA, Branthwaite MA. Domiciliary nocturnal nasal intermittent positive pressure ventilation in hypercapnic respiratory failure due to chronic obstructive lung disease: effect on sleep and quality of life. Thorax 1992; 47: 342348.

88. Berthon-Jones M, Sullivan CE. Time course of change in ventilatory response to $\mathrm{CO}_{2}$ with long-term CPAP therapy for obstructive sleep apnea. Am Rev Respir Dis 1987; 135: 144-147.

89. Lin CC. Effect of nasal CPAP on ventilatory drive in normocapnic and hypercapnic patients with obstructive sleep apnoea syndrome. Eur Respir J 1994; 7: 20052010.

90. Verbraecken J, De Backer W, Willemen M, De Cock W, Wittesaele W, Van de Heyning P. Chronic $\mathrm{CO}_{2}$ drive in patients with obstructive sleep apnoea and effect of CPAP. Respir Physiol 1995; (in press).

91. Udwadia ZF, Santis GK, Steven MH, Simonds AK. Nasal ventilation to facilitate weaning in patients with chronic respiratory insufficiency. Thorax 1992; 47: 715-718.

92. Brochard L, Isabey D, Piquet J, et al. Reversal of acute exacerbations of chronic obstructive lung disease by inspiratory assistance with a face mask. N Engl J Med 1990; 323: $1523-1530$.

93. Shivaram U, Cash ME, Beal A. Nasal continuous positive airway pressure in decompensated hypercapnic respiratory failure as a complication of sleep apnea. Chest 1993; 104: 770-774.

94. Bardsley PA, Howard P, De Backer W, et al. Two years treatment with almitrine bismesylate in patients with hypoxic chronic obstructive airways disease. Eur Respir J 1991; 4: 308-310.

95. De Backer W, Vermeire P, Bogaert E, Janssens E, Van Maele R. Almitrine has no effect on gas exchange after bilateral carotid body resection in severe chronic airflow obstruction. Bull Eur Physiopathol Respir 1985; 21: 427-432.

96. McNicholas WT, Carter JL, Rutherford R, Zamel N, Phillipson EA. Beneficial effect of oxygen in primary alveolar hypoventilation with central sleep apnea. Am Rev Respir Dis 1982; 125: 773-775.

97. Smith PL, Haponik EF, Bleecker ER. The effects of oxygen in patients with sleep apnea. Am Rev Respir Dis 1984; 130: 958-963.

98. Gold AR, Bleecker ER, Smith PL. A shift from central and mixed sleep apnea to obstructive sleep apnea resulting from low-flow oxygen. Am Rev Respir Dis 1985; 132: 220-223.

99. Fletcher EC, Munafo DA. Role of nocturnal oxygen therapy in obstructive sleep apnoea. Chest 1990; 98: 1497-1505.

100. Badr MS, Grossman JE, Weber SA. Treatment of refractory sleep apnea with supplemental carbon dioxide. Am J Respir Crit Care Med 1994; 150: 561-564.

101. Berry RB, Mccasland CR, Light RW. The effect of triazolam on the arousal response to airway occlusion during sleep in normal subjects. Am Rev Respir Dis 1992; 146: $1256-1260$

102. Van Schaardenburg C, De Backer W, Willemen M, et al. Oxygen saturation during sleep at high altitude: influence of different drugs. Eur Respir J 1989; 2: 308S.

103. Dowdell WT, Javaheri S, McGinnis W. Cheyne-Stokes respiration presenting as sleep apnea syndrome. Am Rev Respir Dis 1990; 141: 871-879. 
104. White DP, Zwillich CW, Pickett CK, Douglas NJ, Findley LJ, Weil JV. Central sleep apnea: improvement with acetazolamide therapy. Arch Intern Med 1982; 142: $1816-1819$.

105. Tojima H, Kunitomo F, Kimura H, Tatsumi K, Kuriyama T, Honda Y. Effects of acetazolamide in patients with sleep apnoea syndrome. Thorax 1988; 43: 113-119.

106. Verbraecken J, Willemen M, De Cock W, Van de Heyning $\mathrm{P}$, De Backer W. Central sleep apnea after interrupting long-term acetazolamide administration. Am Rev Respir Dis 1994; 4: A929.

107. Swenson ER, Highes JMB. Effects of acute and chronic acetazolamide on resting ventilation and ventilatory responses in men. J Appl Physiol 1993; 73(1) 230-237.

108. Bickler PE, Litt L, Banville DL, Severinghaus JW. Effects of acetazolamide on cerebral acid-base balance. $J$ Appl Physiol 1988; 65(1): 422-427.

109. Teppema LJ, Rochette F, Demedts M. Ventilatory response to carbonic anhydrase inhibition in cats: effects of acetazolamide in intact $v s$ peripherally chemodenervated animals. Respir Physiol 1988; 74: 373-382.

110. Frankel HM, Garcia E, Malik F, Weiss JK, Weis HR. Effect of acetazolamide on cerebral blood flow and capillary patency. J Appl Physiol 1992; 73(5): 1756-1761.

111. Issa FG, Sullivan CE. Reversal of central sleep apnoea using nasal CPAP. Chest 1986; 90(2): 165-171.
112. Buckle P, Millar T, Kryger M. The effect of short-term nasal CPAP on Cheyne-Stokes respiration in congestive heart failure. Chest 1992; 102: 31-35.

113. Hoffstein V, Slutsky AS. Central sleep apnea reversed by continuous positive airway pressure. Am Rev Respir Dis 1987; 135: 1210-1212.

114. Henke KG, Sullivan CE. Effects of high-frequency pressure waves applied to upper airway on respiration in central apnea. J Appl Physiol 1992; 73(3): 1141-1145.

115. Decker MJ, Haaga J, Arnold JL, Atzberger D, Strohl KP. Functional electrical stimulation and respiration during sleep. J Appl Physiol 1993; 75(3): 1053-1061.

116. Serrette MA, Kryger MH, Anthonisen NR. Ventilatory instability in patients with congestive heart failure and nocturnal Cheyne-Stokes respiration. Sleep 1994; 17(6): 527-534.

117. Yajima T, Koike A, Sugimoto K, Miyahara Y, Marumo F, Hiroe M. Mechanism of periodic breathing in patients with cardiovascular disease. Chest 1994; 106: 142-146.

118. Naughton M, Benard D, Tam A, Rutherford R, Bradley TD. Role of hyperventilation in the pathogenesis of central sleep apneas in patients with congestive heart failure. Am Rev Respir Dis 1993; 148: 330-338.

119. Wilcox I, Grunstein RR, Collins FL, Berthon-Jones M, Kelly DT, Sullivan CE. The role of central chemosensitivity in central apnea of heart failure. Sleep 1993; 16: S37-S38. 